\title{
A review of traffic safety in Finnish municipalities
}

\author{
N. Karasmaa, E. Räty, T. Kari \& T. Ernvall \\ Laboratory of Transportation Engineering, \\ Helsinki University of Technology, Finland
}

\begin{abstract}
A long term road safety programme (called LINTU), funded by the Ministry of Transportation and Communications, Finland, Finnish Road Administration and Finnish Vehicle Administration, was launched in 2002. This research is one of the several independent subprojects of the LINTU-programme. The paper presents a tool for analyzing the state of traffic safety in Finnish municipalities. In addition, variables having the most significant effect on differences between municipalities from traffic safety viewpoint were examined by means of cluster analysis. Results of the cluster analysis proved that it is possible to profile and categorize the municipalities according to the frequency of different accident types and by the degree of urbanization. It is difficult to find any other background variables that explain accidents in municipalities largely because accidents usually happen as a sum of many incidents and human errors. Accordingly, even if some explanatory variables could be found, it would still not be obvious that accidents in different municipalities were caused by the same reasons. It was shown as well that accidents of certain types do not follow any distribution by area. However, it is possible to find indicators that enable the status of traffic safety in municipalities of similar types to be foreseen. The safest municipalities were urban-type municipalities with rather compact land use, whereas the lowest safety level was in rural areas with a high proportion of through traffic.

Keywords: traffic safety, traffic accidents, models, factor analysis, cluster analysis, municipalities, land use, accident risk, vehicle mileage, traffic safety programme.
\end{abstract}




\section{Introduction}

A long-term road safety programme (called LINTU) funded by Ministry of Transportation and Communications, Finland, Finnish Road Administration and Finnish Vehicle Administration, was launched in 2002 [1]. The programme is based on the road safety vision adopted by the Government according to which the road transport system should be designed so that nobody is killed or seriously injured on the roads [2]. The LINTU programme promotes road safety work by, for example, raising the profile of the traffic safety work, strengthening cooperation and information exchange between road safety organisations and by providing new processed data for clarifying the safety vision and making it more concrete. This research is one of the several independent subprojects of the LINTU-programme.

One purpose of this research was to identify and describe the basic risks from road traffic in Finnish municipalities. The main focus of the research is on injury accidents. Another aim was to identify the variables underlying the background to these risks to ensure prerequisites of more detailed traffic safety work at the municipality and national levels. The third purpose was to profile the Finnish municipalities according to their accident history.

Every year some 400 persons are killed and 9000 persons are injured in traffic accidents in Finland [3]. From traffic safety point of view, Finland belongs to the safest third of the EU-countries. The state of traffic safety is better than in Finland only in Netherlands, Great Britain and Sweden when comparing the numbers of fatalities per population [4]. Instead, the fatality rate per annual vehicle mileage is in Finland quite equal with fatality rates of Denmark, Germany and the Netherlands. The rating is better than in Finland only in Sweden and in Great Britain.

Due to scattered community structure Finns are very active road users; on average Finnish passenger cars travel about $17500 \mathrm{~km}$ per year. The general speed limit on the Finnish public road network is $80 \mathrm{~km} / \mathrm{h}$. On I-class highways the speed limit is usually $100 \mathrm{~km} / \mathrm{h}$ and on motorways $120 \mathrm{~km} / \mathrm{h}$. In build-up areas, the speed limit is $50 \mathrm{~km} / \mathrm{h}$, while in more densely populated areas, the speed limit is usually $40 \mathrm{~km} / \mathrm{h}$ or even $30 \mathrm{~km} / \mathrm{h}$. Typical to traffic conditions in Finland is essential effect of seasons. Winters are cold, snowy and dark, while summers are quite warm and the summer days very luminous. During winters the speed limits of $100 \mathrm{~km} / \mathrm{h}$ on most main roads is reduced to $80 \mathrm{~km} / \mathrm{h}$. In addition, a small number of motorways or other roads with separated lanes of opposite driving directions is typical of Finnish road network.

\section{Data}

The research is based on 40159 injury accidents reported by the police in 1997 2002. The accident database consists of 67340 vehicles (= drivers) involved in the accidents. Injured occupants number 52 181, while fatalities number 2513. All fatal road traffic accidents from 1997-2002 are included in the database. However, accidents with less severe consequences, such as accidents settled at 
the accident scene, accidents with very slight injury outcomes or propertydamage-only accidents were not included in the database.

A major proportion of fatal-accident data in the database are related to single vehicle, head-on and overtaking accidents. Those accidents mainly took place in the rural areas. Some $60 \%$ of all accidents considered in the research occurred in urban areas, $20 \%$ in semi-urban areas and $20 \%$ in the rural areas.

One basic geographical and administrative unit used in this research is the municipality. Three larger geographical unities were also considered: a) subregion (number of these: 85) b) computational municipal groups, which are described more precisely in the following section and c) Finland as a whole, but excluding the autonomous island of Åland.

Territorial divisions wider than sub-regions, like provinces, are too inhomogeneous to be used in this research. Therefore we created computational homogenous municipality groups. The groups are based on statistical division of Finnish municipalities according to land use, which is used quite often in the literature. In this text these groups are abbreviated as SGM 1, SGM 2 and SGM 3 (Statistical Grouping of Municipalities) as follows:

- $\quad$ SGM 1: Urban municipalities

- SGM 2: Semi-urban municipalities

- SGM 3: Rural municipalities

Further, we divided each SMG group into five sub-groups according to the population of the municipalities. Finally we got a 3 x 5 table as follows:

Table 1: Numbers of municipalities located into computational homogenous municipality groups. Columns of the matrix classify the municipalities according to the type of land use. Rows classify the municipalities according to population.

\begin{tabular}{|ll|c|c|c|r|}
\hline & \multicolumn{5}{c|}{ SGM groups } \\
Population & \multicolumn{1}{c}{1} & 2 & 3 & SUM \\
\hline 0-5 000 inh. & 1 & $\mathbf{1}$ & $\mathbf{0}$ & $\mathbf{2 1 7}$ & 218 \\
\cline { 2 - 6 } 5001-15 000 inh. & 2 & $\mathbf{1 6}$ & $\mathbf{5 6}$ & $\mathbf{7 1}$ & 143 \\
15 001-35 000 inh. & 3 & $\mathbf{2 6}$ & $\mathbf{1 7}$ & $\mathbf{0}$ & 43 \\
35 001-70 000 inh. & 4 & $\mathbf{1 4}$ & $\mathbf{0}$ & $\mathbf{0}$ & 14 \\
over 70 000 inh. & 5 & $\mathbf{1 0}$ & $\mathbf{0}$ & $\mathbf{0}$ & 10 \\
\cline { 2 - 7 } & & & & & \\
& SUM & 67 & 73 & 288 & 428 \\
\hline
\end{tabular}

The number of observations is large enough for the analyses in 8 cells of Table 1. There are 217 rural municipalities in Finland where population is less than 5000 and only 10 urban cities where population is more than 70000 . The total number of municipalities included in the research is 428 . The existence of zero-cells can be ignored without any confusing effects. It is more important to have reasonable number of observations in the other cells. 


\section{A traffic safety tool for municipalities}

One of the outputs of this research project was a new method of viewing the accident statistics of municipalities by using a Microsoft Excel interface. A lot of information from several databases, like characteristics of road network and population of municipalities, has been integrated to the accident data. The versatility of viewed information is one of the greatest benefits of this tool because, usually, such information must be collected and combined from several databases managed by several separate sources. The tool enables a parallel observation of accident history and accident risks of any two Finnish municipalities from numerous viewpoints. One can for example study how accidents of any two municipalities are distributed by different speed-limit zones, road classes or urbanization levels. There are two main segments in the tool: the first deals with parallel observation of the municipalities, while the second enables the comparison of a single municipality to three wider geographical unities. The tool is developed especially for those nonprofessionals who have to deal with traffic safety questions of municipalities.

Table 2: List of criteria used in sorting different databases for the traffic safety tool.

Annual numbers of accidents 1997-2002

Annual numbers of persons killed in traffic accidents 1997-2002

Accidents by accident types

- head-on, rear-end, crossing, run-off-road, unprotected road users, others

Accidents and killed persons by road categories and road keepers

Accidents by accident type on different road categories

Accidents inside and outside of the build-up areas

Accidents and killed persons by speed limit zones

Accident involvement by driver's age and gender

Accidents by summer and winter seasons

Winter 16.October - 15.April, summer 16.April - 15.October

Involvement of drunken and intoxicated drivers

Accidents by lighting conditions (daylight, twilight, dark, illuminated)

In this tool the accident database was sorted into six groups according to the accident type:

- Single vehicle run-off-road accidents

- Crossing accidents, including cases:

- intersecting directions of travel and/or

- at least one vehicle turning

- Head-on accidents and overtaking accidents

- Rear-end accidents

- Pedestrian, bicycle and moped accidents (accidents involving at least one pedestrian, bicycle or moped = unprotected road users)

- Other accidents (e.g. animal accidents) 
Accident statistics and risk rates of the municipalities are presented in the tool both graphically and numerically. The accident databases are sorted and viewed from several different viewpoints. A list of the criteria used in sorting different data in the tool is showed in Table 2. A screenshot from the tool is shown in Figure 1.

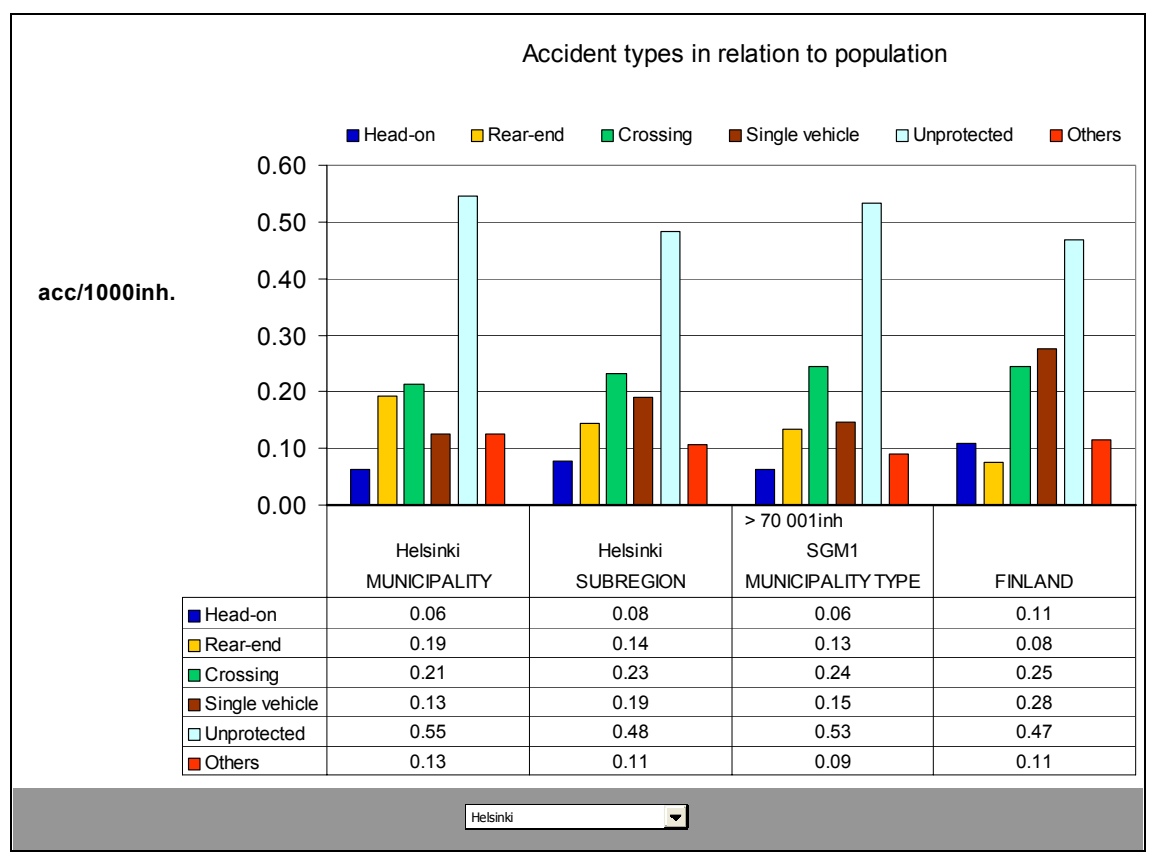

Figure 1: A screenshot from the user interface of traffic safety tool developed as part of the research project. Accidents in Helsinki city are viewed by accident types alongside accidents of three larger regional units.

\section{Cluster analysis}

\subsection{Introduction}

One of the main targets of the research was to find out possibility of creating mathematic models for personal-injury accidents of municipalities. A cluster analysis was used for finding the variables having the most significant effects on the differences of municipalities from traffic safety point of view. One purpose was to create homogenous groups of municipalities according to frequencies of different accident types and according to different variables influencing the backgrounds of the accidents. These groups would illustrate the frequencies of accident types in various types of municipalities and, in addition, the kind of environmental or structural factors contribute to the accidents of different municipalities. 
Cluster analysis classifies a set of observations into two or more mutually exclusive unknown groups based on the combinations of interval variables. The purpose of cluster analysis is to discover a system of organizing observations, in this case municipalities, into groups, where members of the groups have the same properties in common [5]. When doing the cluster analysis, we used an accident-type grouping that was slightly different from that used in the traffic safety tool, because, in this case, we tried to avoid data "clustering" beforehand. This means that pedestrian, bicycle and moped accidents, for example, are not combined as a single group.

In the analysis, each record in the input of the analysis consisted of dozens columns of detailed information on accidents, driver population, land use and the road network of one municipality. Only accident types having the highest probability of severe injuries, or very common accident types, were included in the analysis. For example, the group "other accidents" was not included.

\subsection{The steps of the factor and cluster analyses}

The main steps of the analyses were as follows:

1. First, regression analysis was used to identify the most significant variables explaining different accident types. As a result of the regression analysis, the most significant variables were the degree of urbanization (indicates the proportion of population living in built-up areas), a proportion of 18-24 year old drivers involved in the accidents, a proportion of drivers older than 65 years involved in the accidents, a proportion of males involved in the accidents, a proportion of heavy vehicles involved in the accidents.

2. Factor analysis was used to uncover the latent structure of a set of municipalities. The degree of urbanization and frequencies of different accident types were used as distinctive factors for the municipalities. In addition, the best variables chosen on the basis of the regression analysis were tested in the analysis as well. Factor (and cluster) analyses were made separately for urban and "semi-urban and rural areas".

All the variables examined in the factor and cluster analyses were standardized to mean zero and variance one.

A varimax rotation was used to maximize the variance of the squared loadings of the factor (column) on all the variables (rows) in a factor matrix, which had the effect of differentiating the original variables by the extracted factor. That is, it minimized the number of variables which had high loadings on any one given factor. Thus, each factor tended to have either large or small loadings of particular variables.

The results of the factor analyses are presented in Table 3. The table shows that the frequency of the different accident types and degree of urbanization of the municipalities both expressed quite well the characteristics of certain municipality groups. However, although we had many good explanatory variables for the accidents in the regression analysis, the variables were not very suitable for grouping the municipalities. For 
example, as a result of factor analysis we could get three factors, of which the first two differed from each other according to accident type, but the third differed from the first two only according to the involvement of drivers 18-24 years old.

Consequently, the variables chosen on the basis of the results of the regression analysis seem to explain the accidents of the municipalities in some measure, but the municipalities seem to be very different when comparing the variables influencing the backgrounds of the accidents. In addition, according to the results of the regression analysis, the explanatory power of some of the variables was rather low. The reasons for the low explanatory power of the variables may, on the one hand, be the dominant role of the human factor and, on the other hand, the fact that an accident is usually a combination of several coincidences and factors.

Table 3: $\quad$ Rotated factor pattern.

\begin{tabular}{|l|c|c|c|c|c|}
\hline & \multicolumn{2}{|c|}{ Urban municipalities } & \multicolumn{3}{c|}{ Semi-urban and rural municipalities } \\
\cline { 2 - 6 } & Factor 1 & Factor 2 & Factor 1 & Factor 2 & Factor 3 \\
\hline Head-on acc. & -0.054 & 0.845 & 0.731 & 0.005 & -0.116 \\
\hline Run-off road acc & 0.227 & 0.819 & 0.749 & -0.046 & -0.206 \\
\hline Rear-end acc. & 0.909 & -0.073 & -0.011 & 0.974 & 0.079 \\
\hline Crossing acc. & 0.777 & 0.247 & 0.639 & -0.048 & 0.431 \\
\hline Cycling acc & 0.942 & -0.065 & -0.070 & 0.142 & 0.758 \\
\hline Pedestrian acc. & 0.942 & -0.065 & 0.022 & 0.976 & 0.081 \\
\hline Animal acc. & -0.058 & 0.859 & 0.689 & 0.068 & -0.137 \\
\hline $\begin{array}{l}\text { Degree of urbani- } \\
\text { zation }\end{array}$ & - & - & -0.205 & 0.016 & 0.811 \\
\hline
\end{tabular}

* pedestrian and cycling accidents are considered as a same group in urban areas

3. After factor analysis, factor variables were used as a basis of the k-means clustering [5] (the use of original variables was also tested, but the results based on the factor-variables were more "credible"). Cluster means and the frequency of municipalities included in each cluster are presented in Table 4.

Table 4: $\quad$ Standardized cluster means and the frequency of each cluster.

\begin{tabular}{|c|c|c|c|c|c|c|c|}
\hline & \multicolumn{3}{|c|}{ Urban minucipalities } & \multicolumn{3}{c|}{ Semi-urban and rural municipalities } \\
\hline $\begin{array}{c}\text { Clus } \\
\text { ter }\end{array}$ & $\begin{array}{c}\text { Frequ- } \\
\text { ency }\end{array}$ & Factor 1 & Factor 2 & $\begin{array}{c}\text { Frequ- } \\
\text { ency }\end{array}$ & Factor 1 & Factor 2 & Factor 3 \\
\hline 1 & 12 & -0.520 & 1.588 & 18 & 3.046 & -0.515 & -0.262 \\
\hline 2 & 20 & 1.271 & -0.090 & 71 & 0.003 & 1.277 & -0.727 \\
\hline 3 & 36 & -0.498 & -0.482 & 268 & -0.205 & -0.308 & 0.213 \\
\hline
\end{tabular}

According to cluster analysis the municipalities were grouped into six groups as follows:

Urban cities, where

1. the proportion of run-off-road, head-on and animal accidents is high (12 municipalities) 
2.

the proportion of rear-end and crossing accidents and accidents of unprotected road users is high (20 municipalities)

3. the total number of accidents is smaller than average when compared to the other urban cities (36 municipalities)

Semi-urban and rural municipalities, where

4. the proportion of run-off-road, head-on, crossing and animal accidents is high (18 municipalities)

5. the proportion of rear-end and pedestrian accidents is high (71 municipalities)

6.

a) the degree of urbanization is high compared to other municipalities of a similar type and b) cycling accidents are more common than in the other similar municipalities (268 municipalities).

The total number of municipalities included in the previous groups was 425 because there were three very small municipalities without any accident observations during the years 1997-2002.

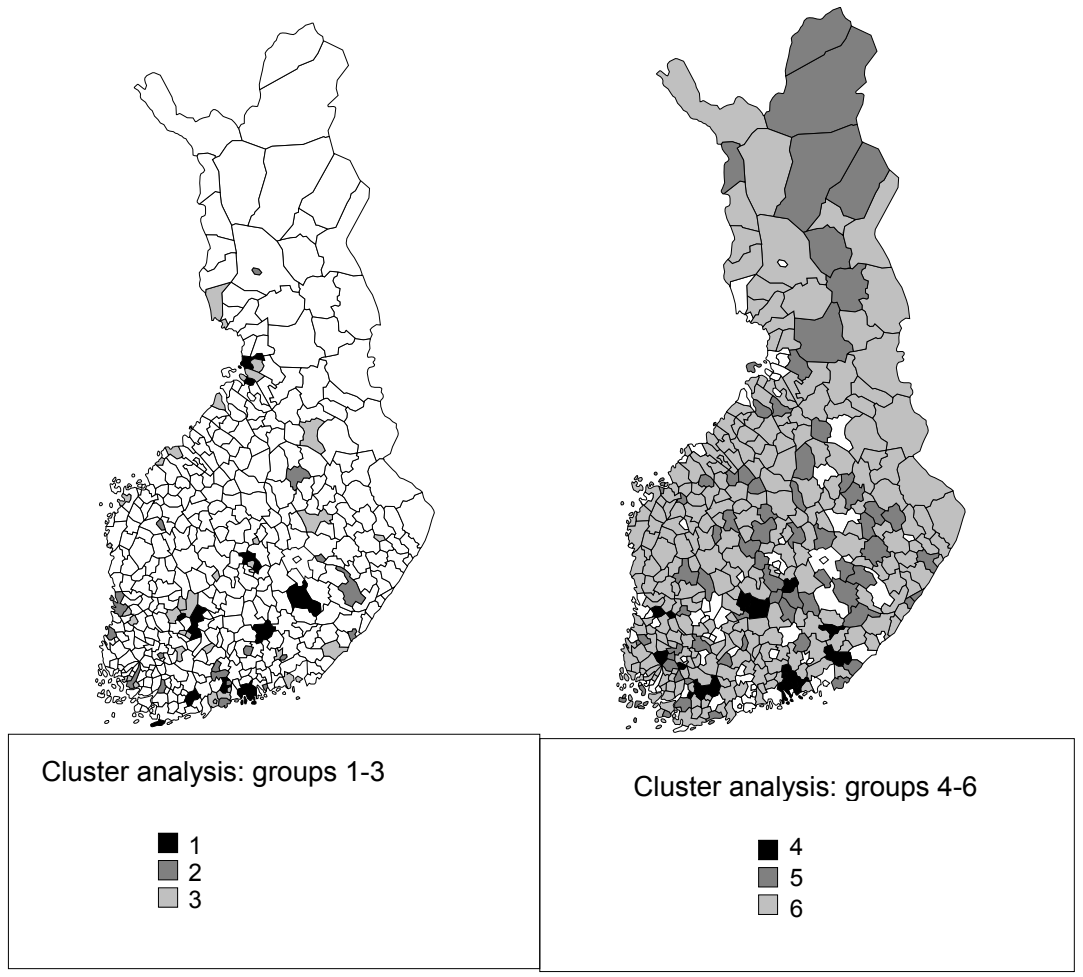

Figure 2: Geographical distribution of municipality groups according to the results of cluster analyses. 
Figure 2 presents the geographical distribution of the groups, while Table 5 presents the most important parameters for each cluster. Some of the indicators presented in the table are not used as the basis of the cluster analyses, but they are presented to get a better overview of the traffic safety situation in different clusters.

When considering the results of the cluster analysis it was stated that, in most municipalities the group-specific conditions were fulfilled quite well. If, for example, a proportion of run-off-road accidents were high in a municipality located in Group 1, the proportion of head-on and animal accidents were high as well. However, it is still possible that a municipality where the proportion of runoff-road accidents is high, but the proportion of animal accidents is near to average, was located in Group 1 or 4.

It should be noted that the municipalities are compared only to the municipalities with a similar type of land use (land use type $1=$ groups 1-3 and land use types 2 and 3 = groups 4-6). This means that for the municipalities of Group 1, for example, the proportions of run-off-road, head-on and animal accidents may not be extremely high when compared to the national level.

Table 5: $\quad$ Accident and road statistics (average values) for different clusters.

\begin{tabular}{|c|c|c|c|c|c|c|c|c|}
\hline GROUP & SGM & $\begin{array}{l}\text { Head-on } \\
\text { acc. } / 1000 \\
\text { inh. }\end{array}$ & $\begin{array}{l}\text { Rear-end } \\
\text { acc. } / 1000 \\
\text { inh. }\end{array}$ & $\begin{array}{l}\text { Crossing } \\
\text { acc. / } 1000 \\
\text { inh. }\end{array}$ & $\begin{array}{l}\text { Run-off- } \\
\text { road acc. I } \\
1000 \text { inh. }\end{array}$ & $\begin{array}{l}\text { Pedestr. } \\
\text { acc. } / 1000 \\
\text { inh. }\end{array}$ & $\begin{array}{c}\text { Cyclist } \\
\text { acc. / } 1000 \\
\text { inh. }\end{array}$ & $\begin{array}{l}\text { Animal } \\
\text { acc. / } 1000 \\
\text { inh. }\end{array}$ \\
\hline 1 & 1 & 0.143 & 0.075 & 0.364 & 0.303 & 0.115 & 0.208 & 0.043 \\
\hline 2 & 1 & 0.075 & 0.101 & 0.536 & 0.210 & 0.234 & 0.384 & 0.015 \\
\hline 3 & 1 & 0.066 & 0.058 & 0.333 & 0.154 & 0.114 & 0.218 & 0.014 \\
\hline 4 & 2 or 3 & 0.528 & 0.148 & 0.625 & 1.303 & 0.048 & 0.088 & 0.302 \\
\hline 5 & 2 or 3 & 0.194 & 0.061 & 0.293 & 0.527 & 0.177 & 0.108 & 0.104 \\
\hline 6 & 2 or 3 & 0.157 & 0.054 & 0.333 & 0.465 & 0.076 & 0.123 & 0.084 \\
\hline GROUP & SGM & $\begin{array}{c}\text { All injury } \\
\text { acc. / } 1000 \\
\text { inh. }\end{array}$ & $\begin{array}{l}\text { All fatal } \\
\text { acc. / } 1000 \\
\text { inh. }\end{array}$ & $\begin{array}{c}\text { All injury } \\
\text { acc. I } \\
\text { vehicle } \\
\text { mileage * }\end{array}$ & $\begin{array}{c}\text { All fatal } \\
\text { acc. I } \\
\text { vehicle } \\
\text { mileage* }^{*}\end{array}$ & $\begin{array}{c}\text { Accidents } \\
\text { on } \\
\text { densely } \\
\text { populated } \\
\text { areas [\%] }\end{array}$ & $\begin{array}{c}\text { Densely } \\
\text { populated } \\
\text { areas [\%] }\end{array}$ & $\begin{array}{c}\text { Annual } \\
\text { mileage, } \\
\text { main } \\
\text { roads } \\
\text { [Mkm] }\end{array}$ \\
\hline 1 & 1 & 1.276 & 0.070 & 12.8 & 0.676 & 53.3 & 90.2 & 687.8 \\
\hline 2 & 1 & 1.516 & 0.058 & 25.9 & 0.945 & 81.9 & 94.9 & 543.7 \\
\hline 3 & 1 & 0.954 & 0.041 & 14.1 & 0.576 & 69.5 & 95.4 & 652.1 \\
\hline 4 & 2 or 3 & 3.111 & 0.268 & 14.1 & 1.231 & 6.9 & 37.8 & 198.2 \\
\hline 5 & 2 or 3 & 1.491 & 0.140 & 10.9 & 1.003 & 18.0 & 42.5 & 141.8 \\
\hline 6 & 2 or 3 & 1.310 & 0.115 & 10.4 & 0.898 & 24.2 & 57.1 & 210.9 \\
\hline
\end{tabular}

* 100 million car kilometres

** Unprotected road users was used as a combined variable in SGM 1 (thick border)

On average, it can be stated that the traffic safety situation of municipalities with more urban land use is better than the situation in other municipalities. Urban cities are safer because their speed limits are lower and therefore a smaller proportion of accidents lead to injuries. Larger cities have also paid more efforts to traffic safety activities than smaller municipalities. Accordingly, the proportion of through traffic including heavy vehicles is quite large in several 
semi-urban and rural municipalities. It should be noted that this research was focused on injury accidents; if property-damage-only accidents were considered in the research, the result would have been different.

Table 5 shows that urban municipalities (Groups 1-3) are safer than semiurban and rural municipalities on average when accidents per inhabitant are considered. When considering accidents per annual mileage the situation is more controversial. In absolute terms, the total number of injury accidents was highest in urban municipalities, and the total number of fatal accidents was highest in rural municipalities. In urban municipalities, the proportion of unprotected road users in fatal accidents was high. The grey area in Table 5 marks the variables used as the basis of the cluster analysis.

Table 6: $\quad$ Extreme values of Finnish municipalities.

\begin{tabular}{|lll|}
\hline & Lowest & Highest \\
Area & $6 \mathrm{~km}^{2}$ & $17300 \mathrm{~km}^{2}$ \\
Population & 240 & 560000 \\
Population density & $0.3 \mathrm{inh} . / \mathrm{km}^{2}$ & $3030 \mathrm{inh} . / \mathrm{km}^{2}$ \\
Degree of urbanization * & $0 \%$ & $96 \%$ \\
Total length of main roads ** & $0 \mathrm{~km}$ & $370 \mathrm{~km}$ \\
Total length of other public roads & $2 \mathrm{~km}$ & $975 \mathrm{~km}$ \\
Total length of streets and private roads & $2 \mathrm{~km}$ & $1276 \mathrm{~km}$ \\
Annual kilometreage of cars & $12000 \mathrm{~km} / \mathrm{a}$ & $20600 \mathrm{~km} / \mathrm{a}$ \\
\hline
\end{tabular}

* degree of urbanization is $0 \%$ in 10 municipalities and 30 municipalities where degree of urbanization is almost $100 \%$

** no main roads at all in 70 municipalities

\section{Discussion}

Even if the Excel tool developed in this project offers the possibility of comparing the municipalities according to their traffic safety level, it is not reasonable to set the municipalities in any order of superiority. Instead of interpreting the results as rankings, they should be interpreted in relation to land use and other traffic-related factors. There is always a risk that ranking the municipalities may cause temporary carelessness towards traffic safety issues among highly ranked municipalities.

It was already known that municipalities vary a lot from, for example, area, population, road network and land-use points of view. Because of summer cottage housing and winter-sport activities, seasonal changes in populations and traffic volumes are quite significant in several municipalities as well. Some extreme values of Finnish municipalities are presented in Table 6. However, this research proved that differences between the risk rates of municipalities are quite independent from those variables.

The observations of this research give more like hints than strong evidence of significant traffic safety differences between municipalities. In addition, the 
results concerning smaller municipalities are somewhat sensitive to annual change variations in accident numbers because the total number of accidents is quite small.

The results of the cluster analysis proved that it is possible to profile and categorize municipalities according to the frequency of different accident types, but it seems much more difficult to profile them according to the explanatory variables of the accidents. Finding only one or two good explanatory variables for each accident type is very difficult, because accidents usually happen as a sum of many incidents and human errors. In addition, even if some explanatory variables can be found, it will still not be obvious that accidents are caused for the same reasons in different municipalities. It was shown as well that accidents of certain types do not follow any distribution by area. However, it is possible to find indicators by which the status of traffic safety of similar types of municipalities can be foreseen. Our research results suggest that the safest municipalities are urban-type municipalities with relatively compact land use, while those with the lowest safety level are in the rural areas with a high proportion of through traffic.

\section{References}

[1] Long-term research and development programme for road safety (LINTU). URL: http://www.lintu.info/english.htm

[2] Road Safety Programme 2001-2005, Ministry of Transport and Communications Finland.

[3] Statistics Finland \& Central Organization for Traffic Safety in Finland, Road Traffic Accidents 2003, Official Statistics of Finland, Statistics Finland: Helsinki, p. 17, 2004.

[4] Statistical Yearbook of Finland 2003, Statistics Finland: Helsinki, CD-rom.

[5] http://www.statsoft.com/textbook/stcluan.html 